\title{
Comprehensive assessment of alcohol-related brain damage (ARBD): Gap or chasm
}

in the evidence?

Lindsay Horton ${ }^{1,2}$

Tim Duffy ${ }^{1}$

Caroline J Hollins Martin ${ }^{3}$

and

Colin R. Martin ${ }^{1,4,5}$

${ }^{1}$ School of Health, Nursing and Midwifery, University of the West of Scotland, Ayr, UK, ${ }^{2}$ Loretto Care, Glasgow, Scotland, ${ }^{3}$ College of Health and Social Care, University of Salford, Greater Manchester, UK, ${ }^{4}$ Faculty of Society and Health, Buckinghamshire New University, Uxbridge, Middlesex, UK and ${ }^{5}$ West London Mental Health NHS Trust, London, UK.

Address for correspondence:

Professor Colin R Martin

Room 2.11

Faculty of Health and Society

Buckinghamshire New University

Uxbridge Campus

106 Oxford Road, Uxbridge, Middlesex, UB8 1NA, UK.

Tel: 01494522141 Extension 2349

Fax: 01494603179

Email: colin.martin@bucks.ac.uk

Key words: assessment; ARBD; cognitive function; memory; neuropsychological testing; thiamine deficiency.

Running head: Assessment of ARBD. 


\section{Accessible Summary:}

- Alcohol-related brain damage (ARBD) causes a broad range of both neurological and neurocognitive impairment

- Mental health nurses are required to provide programs designed to facilitate individuals with chronic alcohol dependency to radically change their drinking behaviour, invariably with an abstinence focus.

- No evidence was found that related to the nutritional and physical intervention needs of this group.

- Most instruments used to access domains relevant to ARBD in terms of providing a comprehensive assessment have not been validated in this group 


\begin{abstract}
Alcohol-related brain damage (ARBD) is primarily caused by chronic alcohol misuse and thiamine deficiency and results in a broad range of impairments. Despite the increasing incidence of ARBD in the UK in recent decades, it is currently underdiagnosed, managed inappropriately and treated inadequately. Moreover, information about assessments for individuals with ARBD is currently absent from clinical guidelines and policy documents. The aim of this paper was to review the evidence relating to the neurological, neuropsychological, psychosocial, physical and nutritional assessment of individuals with ARBD, to identify appropriate assessment tools which could be used to measure and monitor the impact of ARBD over time. A systematic online database search revealed a total of 160 separate references, 133 of which were rejected and 2 of which could not be accessed. 25 papers were included in the review, including 6 neuroimaging studies, 17 neuropsychological studies and 2 studies using psychosocial methods of assessment. A lack of evidence for nutritional and physical assessment of individuals with ARBD was found. The review findings are inconclusive, most instruments currently used in ARBD research have not specifically been validated for use within an ARBD context. Further research is required to identify comprehensive methods of ARBD assessment.
\end{abstract}




\section{Introduction}

Alcohol-related brain damage (ARBD) is an umbrella term encompassing a range of neuropsychiatric conditions, which are caused by long term alcohol misuse and result in structural and functional changes to the brain (MacRae \& Cox, 2003; Zahr et al, 2011). The aetiology of ARBD is varied and includes the direct neurotoxic effects of alcohol on the brain, as well as thiamine depletion (Kopelman, 2009). Severe thiamine deficiency can result in an acute condition known as Wernicke's Encephalopathy (WE), which is a consequence of several factors including inadequate nutritional intake, malabsorption of thiamine and alcoholic liver disease in chronic alcoholics (Isenberg-Grzeda et al, 2012). If WE is not identified and treated, it can lead to Korsakoff's Syndrome (KS), a profound amnesic condition associated with a range of neuropsychological and psychosocial impairments, including severe anterograde and retrograde amnesia, confabulation, spatiotemporal disorientation, executive dysfunction, anxiety and apathy (Thomson et al, 2012a). In terms of prognosis, Smith and Hillman (1999) proposed that recovery rates for individuals receiving treatment for KS can be split into quartiles, with approximately $25 \%$ recovering completely; $25 \%$ recovering significantly; $25 \%$ recovering slightly; and $25 \%$ showing no improvement. Therefore, whilst the majority of individuals with $\mathrm{KS}$ can be expected to recover to some degree, around 25\% will require long-term residential care (Kopelman et al, 2009).

The impact of ARBD is multifaceted and includes neuropathological changes to the brain, neuropsychological dysfunction, reduced quality of life and depression, as well as physical problems related to nutritional deficiencies, damage to the liver, stomach and pancreas (MacRae \& Cox, 2003; Zahr et al, 2011). On-going holistic assessment is therefore required to facilitate the development of specialist ARBD care plans (Mental Welfare Commission for Scotland, 2010). Consistent with this, neuropsychological, psychiatric, social, physical, and functional occupational therapy assessments of daily living, should be conducted following a period of 3-6 weeks abstinence at least every six-months over a period of 2-years, to monitor changes in functioning over time and determine the level of support required by the service user (Ryan \& Butters, 1986; Bruce \& Ritson, 1998; Smith \& Hillman, 1999; Jacques \& Stevenson, 2000; MacRae \& Cox, 2003; Cox et al, 2004). Assessments for ARBD should also incorporate a means of measuring intellectual functioning, as general intelligence along with procedural and semantic memory may remain intact (Thomson et al, 2012). 
Despite the increasing incidence of ARBD in recent decades (Cox et al, 2004), evidence suggests that it is underdiagnosed, managed inappropriately and treated inadequately (Thomson et al, 2012b). Current ARBD service provision is recognised to be inadequate and there is a clear need for appropriate care pathways incorporating specialised assessment and rehabilitation programmes to be developed for this client group (Wilson, 2011). There is currently a lack of clinical guidance relating specifically to the long-term assessment and management of ARBD in the United Kingdom (UK) (Department of Health [DoH], 2009; National Institute for Clinical Excellence [NICE], 2011; Scottish Intercollegiate Guidance Network [SIGN], 2003). Moreover, specific information pertaining to the assessment of ARBD is absent from current Government alcohol strategies in the UK (Scottish Government, 2009; HM Government, 2012).Nevertheless, there exists general recommendations, for example, the Scottish Government (2007) recommends a stepped approach to ARBD assessment, incorporating brief screening tools such as the Mini Mental State Examination (MMSE; Folstein et al, 1975) and Addenbrooke's Cognitive Assessment (ACE; Mathuranath et al, 2000), as well as neuropsychological assessments such as the Weschsler Adult Intelligence Scale (WAIS; Wechsler, 1998); the Weschsler Test of Adult Reading (WTAR; Wechsler, 2001); the Rey Auditory Verbal Learning Test (RAVLT; Schmidt, 1996); the Weschsler Memory Scale (WMS; Wechsler, 1987); and the Delis-Kaplan Executive Function System Subtests (Delis et al, 2001a). As appropriate care depends on the comprehensive assessment of ARBD, specialised assessment procedures are essential to ensure that high quality rehabilitation strategies are implemented and needs-based interventions are available to this client group (MacRae \& Cox, 2003; Mental Welfare Commission for Scotland, 2010). Of particular importance to the mental health services is detection and implementation of strategies to support clients with drink problems, with particular emphasis on helping those with chronic alcohol dependency to stop drinking. To measure the extent of alcohol-induced cognitive damage to the brain caused by excessive alcohol consumption, mental health nurses require to have knowledge of instruments that can be used to measure the neurological damage that can ensue.

This review will critically appraise the evidence relating to neurological, neuropsychological, psychosocial and physical methods of assessing individuals with ARBD. To our knowledge, this is the first paper to systematically review the evidence pertaining to the comprehensive assessment of individuals with ARBD. The key aim of this review is to identify suitable 
assessment tools which could be used in a clinical context to measure and monitor the impact of ARBD over time. It is important that mental health nurses understand more about processes of neurological assessment of quality of life, depression and social/behavioural functioning. Measuring cognitive impairment of those with chronic alcohol dependency is a role that mental health nurses may administrate, with assessment of neurological damage conducted in the addictions unit, outpatients department or the client's home. Identifying suitable assessment tools will be achieved by evaluating the psychometric properties of the assessment tools used within the appraised research papers. The findings from this review have implications for research into methods of assessing individuals with ARBD. As part of a larger body of research, this review also has the potential to influence health and social care practice, as well as clinical guidelines and policy documents relating to the comprehensive assessment of ARBD in the UK and beyond. In response, a protocol may be written for mental health nurses to participate in monitoring improvement or deterioration in neurological function of clients diagnosed with ARBD. Using such validated instruments, success of implemented programs may be monitored in terms of success at improving client abstinence.

\section{Method}

The following online databases were searched to identify English language, peer-reviewed journal articles examining methods of assessment for individuals with alcohol-related brain damage: CINAHL Plus with Full Text; Health Source: Nursing/Academic Edition; MEDLINE; Psychology and Behavioral Sciences Collection; PsycINFO. The PRISMA statement presented by (Moher et al, 2010) was used to guide the literature search strategy (Please see Figure 1 for the PRISMA Flow Diagram). The literature search was conducted on June 17, 2013. No date limitations were set in order to identify all relevant online publications. An initial browse on Google Scholar using the search terms "alcohol-related brain damage/Korsakoff*" AND "assessment" revealed that the existing evidence is focused mainly on the neuropsychological assessment of cognitive functioning in individuals with alcohol-related brain damage. Therefore, a broad literature search strategy was used with the intention of discovering articles focusing on a range of methods of assessment, including neurological, neuropsychological, psychosocial, physical and nutritional assessments in individuals with ARBD. 
The databases were searched using EBSCOHOST by entering combinations of the following search criteria: alcohol-related brain damage/Korsakoff*/Korsakoff's syndrome/WernickeKorsakoff AND assessment. Google Scholar was also searched using combinations of the key words alcohol-related brain damage/Korsakoff*/Korsakoff's syndrome/WernickeKorsakoff AND assessment/“test battery," to identify additional relevant journal articles for inclusion in the review. Additional database searches were conducted using combinations of the following search terms: Korsakoff*/Korsakoff's Syndrome/Wernicke-Korsakoff AND quality of life/depression/anxiety/nutrition*, to locate additional journal articles focusing on the assessment of psychological and nutritional status in individuals with alcohol-related brain damage. A Google Scholar search revealed 1 further article which was suitable for inclusion in the review. Thus, a total of 177 references were retrieved from the online search, 17 of which were duplicates, leaving a total of 160 articles to be screened for eligibility for inclusion in the review.

The titles and abstracts for each article were screened according to the following criteria:

\section{Inclusion criteria}

1. Human study population

2. Primary research study or systematic literature review

3. Papers published in English

4. Participants diagnosed with alcoholic Korsakoff syndrome according to DSM IV or ICD 10 diagnostic criteria

5. Papers focusing on methods of assessment for individuals with alcohol-related brain damage

\section{Exclusion criteria}

1. Papers not published in English

2. Participants with conditions other than alcoholic Korsakoff syndrome, such as dementia, acquired brain injury and psychiatric conditions such as schizophrenia 
3. Papers focusing on treatments, interventions or rehabilitation, prognosis or prevalence of alcohol-related brain damage, rather than methods of assessment

Of the obtained references, 2 articles could not be accessed and 127 were rejected on the basis that they did not meet the inclusion criteria. A further 6 papers were excluded due to close inspection revealing these papers did not reach eligibility criteria. This left a total of 25 articles to be included in the review. Of the papers included in this review, 6 examined neurological assessment, 17 focused on neuropsychological assessment, 1 investigated the assessment of quality of life and 1 paper focused on the assessment of depression and social and behavioural functioning.

\section{Results}

The literature search revealed a total of 25 papers which were suitable for inclusion in the review. 6 papers focused on neuroimaging, 17 papers used neuropsychological assessment methods and 2 papers incorporated psychosocial methods of assessing people with ARBD. None of the identified papers focused on methods of assessing physical functioning and nutritional status, suggesting there is currently a lack of published research concerning nutritional and physical methods of assessing individuals with ARBD. A number of diagnostic categories were reported in the included papers, including Alcohol Amnestic Disorder; Alcohol-Induced Amnesic Syndrome; Alcohol-Induced Persisting Amnestic Disorder; Wernicke-Korsakoff Syndrome and Alcoholic Korsakoff's Syndrome . These diagnoses were reported to be in accordance with Diagnostic and Statistical Manual (DSM) and International Classification of Diseases (ICD) criteria in some of the papers, whilst other papers made no reference to the diagnostic criteria used.

\section{Neuroimaging studies}

Details of the neuroimaging techniques used in the six neuroimaging studies are presented in

Table 1. The methods of neuroimaging used in these studies included Magnetic Resonance Imaging (MRI) (Blansjaar et al, 1992; Emsley et al, 1996; Reed et al, 2003); functional MRI (fMRI) (Caulo et al, 2005); and positron emission tomography (PET) (Paller et al, 1997; Fellgiebel et al, 2003; Reed et al, 2003). All of these papers also incorporated 
neuropsychological methods of assessment, which will be discussed in the neuropsychological assessment section below. Table 1 demonstrates that none of the neurological papers provided an evaluation of neuroimaging techniques as a means of assessing structural and functional brain abnormalities in individuals with ARBD.

\section{TABLE 1. ABOUT HERE}

Taken together, the neurological studies included in this review indicate that KS is associated with structural damage to subcortical cerebral regions (Emsley et al, 1996), the thalamus, cerebellum and mammillary bodies in the brain (Blansjaar et al, 1992; Reed et al, 2003). The findings also indicate that $\mathrm{KS}$ is associated with dysfunction in frontal, parietal and cingulate cortical regions (Paller et al, 1997), as well as impaired thalamic function (Fellgiebel et al, 2003; Reed et al, 2003). A major weakness of the studies presented within this review is the small sample sizes, which limits the generalizability of their findings. Moreover, as only six neuroimaging studies were identified for this review, the current evidence relating to structural and functional neuropathology in KS patients is limited and caution should be exercised when interpreting the findings presented above. Considering advancements made in recent years in neuroimaging, it is also noted that some of these studies are quite old. A broader limitation of these studies relates to the validity of neuroimaging techniques themselves. In particular, questions can be raised concerning the functional specificity of neuroimaging techniques, as well as the consistency of findings from neuroimaging studies (Wager et al, 2008).

\section{Neuropsychological Assessments}

Seventeen of the papers included in this review used neuropsychological assessments to investigate the impact of ARBD on cognitive functioning. A range of neuropsychological methods of assessment were also utilised in the six neuroimaging papers discussed above. A total of 58 neuropsychological methods of assessment were identified across the seventeen neuropsychological and six neuroimaging papers. These assessment tools can be divided into three main areas, namely general cognitive and intellectual functioning, executive functioning 
and memory impairment. The methods of assessment utilised in these papers are presented in Table 2. Due to the large number of neuropsychological instruments identified within the reviewed papers, brief descriptions of the assessment tools occurring in three or more papers are provided; whilst the instruments occurring less frequently are listed as miscellaneous, unless the papers contained information pertaining to their psychometric properties. The most commonly used neuropsychological assessments in the reviewed papers were the Wechsler Adult Intelligence Scale (WAIS; Wechsler, 1998) and the FAS verbal fluency test (Spreen \& Strauss, 1998), which occurred in 14 and 10 of the papers, respectively. The Wechsler Memory Scale (WMS; Weschler, 1987) occurred in 9 of the papers, whilst the Stroop Test (Golden \& Freshwater, 2002) occurred in 7 papers. Moreover, the Trail Making Test (TMT; Reitan \& Wolfson, 1993); Mini Mental State Examination (MMSE; Folstein et al, 1975); National Adult Reading Test (NART; Nelson \& Willison, 1991); Wisconsin Card Sort Test (WCST; Kongs et al, 2000); and the Rey Osterreith Complex Figure (Osterreith, 1944) all occurred in 6 of the papers.

\section{TABLE 2. ABOUT HERE}

Table 2 reveals that the reviewed papers contain a considerable lack of information about the psychometric properties of the neuropsychological instruments. Details about validity and reliability were provided for only 7 of the 58 identified neuropsychological assessment tools. Most of the psychometric information about the identified neuropsychological instruments was provided in the paper by Maharasingam et al (2013). These authors affirmed that the reliability coefficients for all subtests of the WAIS-III are high and range between 0.80 and 0.90. Maharasingam et al also stated that various versions of the NART, (Nelson \& Willison, 1991) have reliability estimates of above 0.90 , making it one of the most reliable clinical tests of premorbid intellectual functioning. These authors also provided information about the inter-rater reliability of the Behavioural Assessment of the Dysexecutive Syndrome test (BADS) which has been demonstrated to be above 0.88 by the creators of the test. They also presented information about the reliability of Trail A of the TMT, (Reitan \& Wolfson, 1993) and declared that its' test-retest reliability is relatively high ( 0.79 at 11 month follow-up), whilst its' inter-rater reliability is high at 0.94. Furthermore, they affirmed that the inter-rater reliability of the Doors and People test is very high at 0.98 . Nevertheless, the information 
presented by Maharasingam et al does not specifically relate to the psychometric properties of these instruments in an ARBD context. Thus, there is no evidence within this paper to suggest that these instruments have been evaluated for use with individuals with ARBD and they may therefore not be appropriate for use within an ARBD context.

Van Den Berg et al (2009) and Wester et al's (2013) papers were the only two to investigate the psychometric properties of an assessment tool in relation to individuals with ARBD. Wester et al's (2013) recent study aimed to evaluate the applicability of the Dutch version of the Rivermead Behavioural Memory Test - Third Edition (RBMT-3; Wilson et al, 2008) when used with individuals with KS. The findings from this study revealed that patients with KS performed significantly more poorly on the RBMT-3 subtests (all $P$-values, 0.0005 ) than healthy controls and chronic alcoholics, suggesting that this instrument is able to discriminate between individuals with KS and those with milder alcohol-related memory impairments. A Global Memory Index cut-off at 87.5 revealed that the sensitivity of the RBMT-3 was good at 0.8 , whilst its' specificity was adequate at 0.62 . Thus, the authors of this study concluded that the RBMT-3 has good diagnostic accuracy when used with individuals with ARBD.

Van Den Berg et al's (2009) factor analytic study involved the collection of normative data to establish the validity of the Brixton Spatial Anticipation Test as a test for executive dysfunction in different groups of clinical patients, including 41 patients with KS. The Brixton Spatial Anticipation Test (Burges \& Shallice, 1997) specifically measures one aspect of executive functioning, namely the ability to follow and detect a rule. Therefore, it is not a comprehensive assessment of executive dysfunction. The existing evidence for the test-retest reliability of the Brixton Spatial Anticipation Test indicates a coefficient of 0.71 (Burgess \& Shallice, 1997), suggesting that the reliability of the instrument is acceptable, but not high. The findings from Van Den Berg et al's study demonstrated that KS patients had impaired performance on the Brixton Spatial Anticipation Test in comparison to normative data from age and education-matched healthy controls. Moreover, as correlations were found between the Brixton Spatial Anticipation Test and the Trail Making Test, the authors concluded that the Brixton test has adequate convergent validity when used with clinical populations. The findings also revealed that the Brixton test had satisfactory sensitivity and specificity when comparing healthy controls to patients with KS (0.74), suggesting that the Brixton Spatial Anticipation Test could be used as an accurate diagnostic test for clients with ARBD. Nevertheless, as the test-retest reliability of the Brixton Spatial Anticipation Test was found 
to be relatively low (0.61), the test may not accurately measure changes over time in clinical populations, such as those with ARBD.

The seventeen neuropsychological studies included in this review aimed to investigate the impact of ARBD on cognitive functioning. A wide range of neuropsychological methods of assessment were used to measure global cognitive and intellectual functioning, executive functioning and memory impairment in individuals with ARBD (See Table 2). Sixteen of the neuropsychological studies included in this review had between-groups designs, whilst only one of the studies had a longitudinal design (Fujiwara et al, 2008). Therefore, the majority of the studies provide no information about the cognitive changes that may occur in individuals with ARBD over time. Nevertheless, characteristics such as age, gender and level of education were controlled in most of the between-groups studies, to ensure that the control groups matched patients with ARBD.

As a whole, the findings from the neuropsychological studies demonstrated that individuals with ARBD are significantly impaired on a range of cognitive functions, including memory and executive functions such as decision-making, time estimation, affective judgements and verbal fluency. The findings from these studies also suggest that despite experiencing profound memory impairment and executive dysfunction, general intellectual functioning remains relatively intact in individuals with ARBD. Nevertheless, it is clear from this review that the instruments used in these studies have not been validated for use within an ARBD context. Moreover, as the sample sizes in the studies were relatively small with numbers ranging from 5 (Douglas \& Wilkinson, 1993) to 41 (Van Den Berg et al, 2009), the generalizability of their findings may be limited.

\section{Psychosocial Assessments}

Table 3 provides a summary of the psychosocial methods of assessing individuals with ARBD. Only two of the papers identified for inclusion in this review focused specifically on the use of psychosocial methods of assessing individuals with ARBD (Irvine \& Mawhinney, 2008; Oudman \& Zwart, 2012). Psychosocial methods of assessment were also used in three 
of the papers discussed above (Blansjaar et al, 1992; Douglas \& Wilkinson, 1997; OscarBerman et al, 2004). Blansjaar et al (1992) used the Brief Psychiatric Rating Scale to screen for psychopathology, such as depression, anxiety and psychosis. Moreover, Douglas and Wilkinson (1997) used the Profile of Mood States (POMS) and the Geriatric Depression Scale (GDS) to assess affective state and depression severity. Oscar-Berman et al (2004) used the Hamilton Depression Scale (HAM-D) to measure depression severity. However, a systematic review of the HAM-D demonstrated that it is an insensitive measure of depression with several psychometric weaknesses, including poor inter-rater and test-retest reliability (Bagby et al, 2004). Thus, caution should be exercised when using this instrument to measure depression severity.

\section{TABLE 3. ABOUT HERE}

Oudman and Zwart (2012) used an observational dementia-specific quality of life (QoL) instrument called the Qualidem scale in their study. The psychometric properties of the Qualidem questionnaire have been evaluated in the context of dementia (Ettema et al, 2007; Bouman et al, 2011). Nevertheless, as Oudman and Zwart's study is the only published article focusing on QoL in patients with KS, there is limited evidence for the clinical utility of this instrument in an ARBD context. Oudman and Zwart's findings demonstrated that KS patients QoL was moderate (mean $=70 \%$ ), with KS patients scoring better than patients with dementia on the "restless tense behaviour," "social relations," "having something to do" and "positive affect" subscales. However, KS patients scored significantly lower than those with dementia on the "feeling at home" subscale. Thus, although patients with KS displayed an overall better QoL than those with dementia, the evidence from Oudman et al's (2012) paper suggests that patients with KS do not feel at home in traditional nursing home facilities.

A 12-month longitudinal study by Irvine \& Mawhinney (2008) used two subscales of the Life Skills Profile (LSP), along with the Center for Epidemiologic Studies Depression (CES-D) scale, to investigate changes in social and behavioural functioning in four males with KS (aged 38-57) living in a specialist supported living unit in Northern Ireland. The LSP is a strengths-based instrument which focuses on what people are capable of doing by measuring 
their functioning on a four-point scale. Although the LSP was originally developed for individuals with schizophrenia, it has been used to measure functioning in a range of client groups (Rosen et al, 2006). Irvine and Mawhinney included the "self-care ability" and "social contact" subscales of the Life Skills Profile (LSP), although they provided no rational for the omission of the "communication," "anti-social" and "responsibility" subscales. The findings revealed that self-care ratings were above mid-range at baseline and fluctuated slightly over the 12-month study period due to mental health and behavioural issues. Moreover, social contact scores were low but relatively stable over the study period. Depression severity, as measured by the CES-D also fluctuated in this study, with 3 of the participants remaining within the severe depression range over the study period. The CES-D scale is a valid 20-item measure of depressive symptomatology with high internal consistency and adequate testretest reliability (Radloff, 1977). It was originally developed for use with the general population and its' psychometric properties have been evaluated in relation to various clinical conditions, including depression and dementia. Nevertheless, as the CES-D has not been validated for use with individuals with ARBD caution should be exercised when interpreting Irvine and Wawhinney's findings. 


\section{Discussion}

This review indicates that researchers use a variety of assessment tools to investigate the neurological, cognitive and psychosocial impact of ARBD. The papers included in the review provide limited information about the validity and reliability of the instruments used to assess individuals with ARBD. Most of the papers focused on explaining the nature of the impairments resulting from $A R B D$, rather than evaluating the psychometric properties of the instruments used to assess these impairments. Thus, the clinical utility of the identified instruments is unknown within an ARBD context. The majority of the papers included in the review used neuropsychological methods of assessment, whilst six papers used neuroimaging techniques and four of the papers used psychosocial assessment tools. Taken together, these findings indicate that the existing evidence for the comprehensive assessment of individuals with ARBD is limited and there is a clear need for further research to be conducted to establish a robust evidence base in this area. It is salient that mental health nurses hold awareness of the utility of instruments that can be used to measure neurological, cognitive and psychosocial impact of ARBD. There is also room for research to be conducted to measure improvement and deterioration of clients' condition in response to scheduled treatment protocols designed and implemented to help them control their alcohol intake.

Within the reviewed papers, the two most frequently occurring neuropsychological assessment tools were the Wechsler Adult Intelligence Scale and the FAS Test, followed by the Wechsler Memory Scale (WMS), the Stroop Test, the Trail Making Test (TMT), the Mini Mental State Examination (MMSE), the National Adult Reading Test (NART), the Wisconsin Card Sort Test (WCST) and the Rey Osterreith Complex Figure. Information was provided about the psychometric properties of the Brixton Spatial Anticipation Test and Doors and People Test. However, these instruments occurred only once in the reviewed papers. The only instruments to be evaluated for use with individuals with ARBD were the Brixton Spatial Anticipation Test (Van Den Berg, 2009) and the Rivermead Behavioural Memory Test (Wester et al, 2013). It is important that mental health nurses are aware that these assessment tools do not provide a comprehensive assessment of individuals with $\mathrm{ARBD}$, as the Brixton test assesses only one aspect of executive functioning; whilst Rivermead Behavioural Memory Test does not assess semantic and working memory. The lack of psychometric information in the reviewed papers raises the possibility that researchers 
and mental health practitioners may commonly use instruments which are not validated for use with individuals with ARBD. Thus, it can be argued that the findings from these papers should be interpreted with caution. It is also an area for further research by mental health nurses and addiction experts.

Beyond the context of ARBD, there is mixed psychometric data for the most commonly used instruments identified in this review. The validity and reliability of the MMSE, WAIS and WMS are well established (Chlebowski, 2011; Saklofske \& Schoenberg, 2011; Schatz, 2011). Moreover, the TMT has been found to be a highly sensitive measure of attention when used with people with brain injury (Meyers, 2011). The reliability of the Stroop colour-word test has been demonstrated to be acceptable (Rozenblatt, 2011). The reliability of the NART has been demonstrated to be high, although its' validity has not been established (Venegas \& Clark, 2011). The validity and reliability of the WCST have been found to fluctuate depending on the level of skill and training of the administrator, and researchers have acknowledged that practice effects are a key limitation of this instrument when it is repeated multiple times (Kolakowsky-Hayner, 2011). Moreover, findings have been inconsistent for the validity and reliability of the FAS verbal fluency test when used with individuals with neurological damage, suggesting it may not be an appropriate instrument to use with individuals with ARBD (Patterson, 2011).

The six neuroimaging studies included in this review provided information about the impact of ARBD on the structure and function of the brain. However, whilst neuroimaging research is a useful means of investigating the neuropathology of ARBD, neuroimaging techniques may not be financially feasible or practicable within a clinical context. Neuroimaging may also be of limited value as a means of informing interventions for individuals with ARBD, as the consistency of findings from neuroimaging studies and the functional specificity of the techniques have been questioned (Wager et al, 2008). Further primary research and metaanalysis is therefore warranted to synthesise the findings from neuroimaging studies (Wager et al, 2008), and to provide robust evidence for the validity and value of undertaking neuroimaging assessments within an ARBD context. The existing psychometric data for the psychosocial instruments identified in this review is limited. Several psychometric weaknesses have been reported for the HAM-D as a measure of depression (Bagby et al, 
2004). Moreover, as the Qualidem, LSP and CES-D have not specifically been evaluated for use within an ARBD context, they may not be appropriate methods of assessing quality of life, life skills and depression severity in individuals with ARBD.

As a whole, the reviewed papers have several limitations which make it difficult to ascertain which instruments are most appropriate for undertaking a comprehensive assessment of individuals with ARBD. Firstly, there appears to be little validation for the use of the identified assessment tools in an ARBD context, as the existing research focusing specifically on evaluating the psychometric properties of assessment tools in an ARBD context is limited. The small sample sizes in the reviewed studies suggest that the existing evidence may be of limited generalizability, as the samples in the reviewed studies may have been biased. Despite experiencing impaired functioning during everyday life, individuals have been demonstrated to perform within the normal range on traditional neuropsychological tests, such as the Wisconsin Card Sorting Test and Stroop Test (Rozenblatt, 2011). Therefore, questions can be raised about the extent to which the identified neuropsychological assessments are able to predict everyday functioning in individuals with ARBD (Shallice \& Burgess, 1991). Two ecologically valid neuropsychological assessment tools are the Behavioural Assessment of the Dysexecutive Syndrome (BADS) and the Rivermead Behavioural Memory Test (RBMT-3), which provide information about the everyday problems individuals may encounter as a result of executive dysfunction and memory impairment (Norris \& Tate, 2000; Wester et al, 2013). These instruments may therefore be valuable within a clinical ARBD context, as they can be used by practitioners to identify problems in daily functioning, which can then be targeted in interventions (Rozenblatt, 2011).

This review revealed that there is a lack of evidence for the nutritional and physical assessment of individuals with ARBD. Comorbidities such as liver dysfunction may explain this lack of evidence (Zahr et al, 2011), as research focusing on physical and nutritional methods of assessment may incorporate heterogeneous samples comprising of alcoholics who may or may not also have ARBD. If this is case, the use of wider search parameters within this review may have identified research pertaining to nutritional and physical methods of assessing individuals who have physical problems as a result of chronic alcohol misuse. 
The papers included in this review provided no information about how often assessments should be repeated with individuals with ARBD. Moreover, few papers measured changes in functioning over time. Nevertheless, as functioning can be expected to improve to some extent in approximately three-quarters of individuals with ARBD (Kopelman et al, 2009), it has been recommended that individuals with ARBD should be assessed at least every six months for a period at least two years (Bruce \& Ritson, 1998; Smith \& Hillman, 1999; Jacques \& Stevenson, 2000; MacRae \& Cox, 2003). Important considerations when undertaking repeated assessments are test-retest reliability and practice effects. Thus, instruments with good test-retest reliability should be chosen and practice effects should be avoided by establishing the optimum frequency for undertaking repeated assessments within an ARBD context.

One of the key implications arising from this review is that further research is needed to identify a comprehensive battery of assessments which can be used specifically with individuals with ARBD. There are opportunities herein for mental health nurses to develop and measure success of delivering particularised care schedules and specialist assessment packages. The development of a specialist assessment package for ARBD has implications for health and social care practice, as it could be used to measure and monitor the impact of ARBD over time and could also be used to inform evidence-based interventions. The creation of a comprehensive assessment package for individuals with ARBD also has implications at a policy level, as it could be incorporated into alcohol strategy documents, as well as clinical guidelines relating to the assessment and rehabilitation of individuals with ARBD by mental health teams in addiction units.

\section{Conclusion}

This review indicates that a variety of methods have been utilised to assess individuals with ARBD, despite the absence of validation for these instruments within an ARBD context. The 
review also revealed that most of the existing ARBD research uses neuropsychological methods of assessment, whilst there is limited evidence for the use of psychosocial assessments and a clear lack of evidence focusing on nutritional and physical methods of assessing individuals with ARBD. This review highlights the importance of ensuring that assessment tools are valid and reliable for use within an ARBD context. Moreover, as the majority of individuals with ARBD can be expected to improve to some degree, instruments must be able to accurately measure changes in functioning over time. This review demonstrates that there is currently no comprehensive assessment battery for use specifically within an ARBD context. Thus, there is a clear need for the development of a specialist assessment package to measure and monitor functioning in individuals with ARBD, and to inform holistic evidence-based interventions for this client group. This area of development lends itself to both clinical application and research development by mental health nurses working in the area of addictions. Protocols for scheduled treatment of chronic alcohol consumption and application of instruments to measure effectiveness at reducing ARBD may be developed, adjacent to validating and reliability testing of measuring tools involved using psychometrics.

Acknowledgements

We would like to thank two expert reviewers for their extremely helpful and focused comments which were extremely helpful in the revision of an earlier version of this manuscript. This work was in part supported by a Knowledge Transfer Partnership (KTP) project grant awarded to and 


\section{References}

Bagby, R.M., Ryder, A.G., Schuller, D.R. \& Marshall, M.B. (2004). The Hamilton Depression Rating Scale: Has the Gold Standard Become a Lead Weight? The American Journal of Psychiatry, 161, 2163-2177.

Beaunieux, H., Desgranges, B., Lalevee, C., de la Sayette, V., Lechevalier, B. \& Eustache, F. (1998). Preservation of cognitive procedural memory in a case of Korsakoff's syndrome: Methodological and theoretical insights. Perceptual and Motor Skills, 86, 1267-1287.

Blansjaar, B.A., Vielvoye, J.J., Van Dijk, G. \& Rijnders, R.J.P. (1992) Similar brain lesions in alcoholics and Korsakoff patients: MRI, psychometric and clinical findings. Clinical Neurology and Neurosurgery, 94, 197-203.

Bouman, A.I.E., Ettema, T.P., Wetzels, R.B., van Beek, A.P.A., de Lange, J., Droes, R.M. (2011). Evaluation of Qualidem: a dementia-specific quality of life instrument for persons with dementia in residential settings; scalability and reliability of subscales in four Dutch field surveys. International Journal of Geriatric Psychiatry, 26, 711-722.

Brand, M., Fujiwara, E., Kalbe, E., Steingass, H.P., Kessler, J. \& Markowitch, H.J. (2003). Cognitive Estimation and Affective Judgements in Alcoholic Korsakoff Patients. Journal of Clinical \& Experimental Neuropsychology, 25, 324.

Brand, M., Fujiwara, E., Borsutzky, S., Kalbe, E., Kessler, J. \& Markowitsch, H.J. (2005). Decision-Making Deficits of Korsakoff Patients in a New Gambling Task With Explicit Rules: Associations With Executive Functions. Neuropsychology, 19, 267-277.

Bruce, M. \& Ritson, B. (ed.) (1998). Substance Misuse, Edinburgh: Churchill Livingstone.

Burgess, P. \& Shallice, T. (1997). The Hayling and Brixton Tests. Test Manual. Bury St Edmunds, UK Thames Valley Test Company.

Caulo, M., Van Hecke, J., Toma, L., Ferretti, A., Tartaro, A., Colosimo, C., Romani, G.L. \& Uncini, A. (2005). Functional MRI study of diencephalic amnesia in Wernicke-Korsakoff syndrome. Brain: A Journal of Neurology, 128, 1584-1594.

Cheblowski, C. (2011). Wechsler Memory Scale All Versions. In: Kruezer (ed.).

Encyclopedia of Clinical Neuropsychology. New York: Springer Science \& Business Media.

Cox, S., Anderson, I. \& McCabe, L. (2004). A Fuller Life: Report of the Expert Group on Alcohol Related Brain Damage. University of Stirling: Dementia Services Development Centre.

Delis, D. C., Kaplan, E., \& Kramer, J. H. (2001a). Delis-Kaplan executive function system: Examiner's manual. San Antonio, TX: The Psychological Corporation.

Department of Health. (2009). Signs for Improvement: Commissioning interventions to reduce alcohol-related harm. London: Department of Health. 
Douglas, J. \& Wilkinson, D.A. (1993). Evidence for normal emotional responsivemess in alcoholic Korsakoff's syndrome in the presence of profound memory impairment. Addiction, $88,1637-1645$.

Emsley, R., Smith, R., Roberts, M. \& Kapnias, S. (1996). Magnetic resonance imaging in alcoholic Korsakoff's syndrome: Evidence for an association with alcoholic dementia. Alcohol and Alcoholism, 31, 479-486.

Ettema, T.P., Droes, R.M., de Lange, J., Mellenbergh, G.L \& Ribbe, M.W. (2007). QUALIDEM: development and evaluation of a dementia specific quality of life instrument. Scalability, reliability and internal structure. International Journal of Geriatric Psychiatry, 22, 549-556.

Fellbiebel, A., Scheurich, A., Siessmeier, T., Schmidt, L.G. \& Bartenstein, P. (2003). Persistence of disturbed thalamic glucose metabolism in a case of Wernicke-Korsakoff's syndrome. Psychiatry Research: Neuroimaging, 124, 105-112.

Fujiwara, E., Brand, M., Borsutzky, S., Steingass, H.P. \& Markowitsch, H.J. (2008). Cognitive performance of detoxified alcoholic Korsakoff syndrome patients remains stable over two years. Journal of Clinical \& Experimental Neuropsychology, 30, 576-587.

Folstein, M., Folstein, S.E. \& McHugh, P.R. (1975) "Mini-Mental State" a practical method for grading the cognitive state of patients for the clinician. Journal of Psychiatric Research, $12,3,189-198$.

Golden, C. \& Freshwater, S. 2002. A manual for the adult Stroop Colour and Word Test. Chicago, IL: Stoelting.

HM Government (2012). The Government's Alcohol Strategy. London: Stationary Office. Irvine, C. \& Mawhinney, S. (2008). Functioning of individuals with Korsakoff's syndrome: a pilot study of supported group living in Northern Ireland. Mental Health Review Journal, 13, 16-23.

Isenberg, G.E., Kutner, H.E. \& Nicolson, S.E. (2012). Wernicke-Korsakoff syndrome: Under-recognized and under-treated. Psychosomatics: Journal of Consultation Liason Psychiatry, 53, 507-516.

Jacques, A. \& Stevenson, G. (2000). Korsakoff's syndrome and other chronic related brain damage in Scotland. Stirling Dementia Service Development Centre.

Joyce, E.M. \& Robbins, T.W. (1991) Frontal lobe function in Korsakoff and non-Korsakoff alcoholics: Planning and spatial working memory. Neuropsychologia, 29, 8, 709-723.

Kessler, J., Irle, E. \& Markowitsch, H.J. (1986). Korsakoff and alcoholic subjects are severely impaired in animal tasks of associative memory. Neuropsychologia, 24, 5, 671-680. 
Kolakowsky-Hayner, S. (2011). Wisconsin Card Sorting Test. In: Kreuzer (ed.).

Encyclopedia of Clinical Neuropsychology. New York: Springer Science \& Business Media.

Kongs, S.K., Thompson, L.L., Iverson, G.L. \& Heaton, R.K. (2000) Wisconsin Card Sorting Test-64 card computerised version. Odessa: Psychological Assessment Resources.

Kopelman, M.D., Thomson, A.D., Guerrini, I. \& Marshall, E.J. (2009). The Korsakoff Syndrome: Clinical Aspects, psychology and treatment. Alcohol and Alcoholism, 44, 148154.

Labudda, K., van Rothkirch, N., Pawlikowski, M., Laier, C. \& Brand, M. (2010).

Categorization Abilities for Emotional and Nonemotional Stimuli in Patients with Alcoholrelated Korsakoff Syndrome, Cognitive Behavioural Neurology, 23, 2, 89-97.

MacRae, S. \& Cox, S. (2003). Meeting the needs of people with alcohol-related brain damage: A literature review on the existing and recommended service provision and models of care. University of Stirling.

Maharasingam, M., MacNiven, J.A.B. \& Mason, J. (2013). Executive functioning in chronic alcoholism and Korsakoff syndrome. Journal of Clinical and Experimental Neuropsychology, 35, 501-508.

Mathuranath PS, Nestor PJ, Berrios GE, et al. (2000). A brief cognitive test battery to differentiate Alzheimer's disease and frontotemporal dementia. Neurology 55(11): 16131620.

Mental Welfare Commission for Scotland. (2010). Missed Opportunities: Findings from our visits to people with Acquired Brain Injury and Alcohol Related Brain Damage. Edinburgh: Mental Welfare Commission for Scotland.

Meyers, J.E. (2011). Trail Making Test. In: Kreuzer (ed.). Encyclopedia of Clinical Neuropsychology. New York: Springer Science \& Business Media.

Moher, D., Liberati, A., Tetzlaff, J. \& Altman, D.G. (2009). Preferred reporting for systematic reviews and meta-analyses: the PRISMA statement. Journal of Clinical Epidemiology, 62, 1006-1012.

National Institute for Health and Clinical Excellence. (2011). Alcohol-use disorders: diagnosis, assessment and management of harmful drinking and alcohol dependence. Manchester: National Institute for Health and Clinical Excellence.

Nelson, H.E. \& Willison, J.R. (1991). The Revised National Adult Reading Test-Test Manual. Windsor, UK: NFER-Nelson.

Norris, G. \& Tate, R.L. (2000). The Behavioural Assessment of the Dysexecutive Syndrome (BADS): Ecological, Concurrent and Construct Validity. Neuropsychological Rehabilitation, $10,33-45$. 
Oscar-Berman, M., Kirkley, S.M., Gansler, D.A. \& Couture, A. (2004). Comparisons of Korsakoff and non-Korsakoff alcoholics on neuropsychological tests of prefrontal brain functioning. Alcoholism: Clinical and Experimental Research, 28, 667-675.

Osterreith, P.A. (1944). Le Test du copie d'une figure complexe/test of copying a complex figure: Contribution to the study of perception and memory. Archives of Psychology, 30, 206-356.

Oudman, E. \& Zwart, E. (2012). Quality of Life of Patients with Korsakoff's Syndrome and Patients with Dementia: A Cross Sectional Study. Journal of the American Medical Directors Association, 13, 778-781.

Paller, K.A. \& Acharya, A. (1997). Functional Neuroimaging of cortical dysfunction in alcoholic Korsakoff's syndrome. Journal of Cognitive Neuroscience, 9, 277.

Parmalee, P.A. \& Katz, I.R. (1990). Geriatric Depression Scale. Journal of the American Geriatrics Society, 38.

Patterson, J. (2011). F-A-S Test. Encyclopedia of Clinical Neuropsychology. New York: Springer Science \& Business Media.

Pitel, A.L., Beaunieux, H., Witkowski, T., Vabret, F., de la Sayette, V., Viader, F., Desgranges, B. \& Eustache, F. (2008). Episodic and working memory deficits in alcoholic Korsakoff patients: The continuity theory revisited. Alcoholism: Clinical and Experimental Research, 32, 1229-1241.

Radloff, L.S. (1977). The CES-D Scale: A self-report depression scale for research in the general population. Applied Psychological Measurement, 1, 385-401.

Reed, L.J., Lasserson, D., Marsden, P., Stanhope, N., Stevens, T., Bello, F., Kingsley, D., Colchester, A. \& Kopelman, M.D. (2003). FGT-PET findings in the Wernicke-Korsakoff syndrome. Cortex: A Journal Devoted to the Study of the Nervous System and Behaviour, 39, 1027-1045.

Reitan, R.M. \& Wolfson, D. (1993). The Halstead-Reitan Neuropsychological Test Battery: Theory and clinical interpretation. Tucson, AZ: Neuropsychology Press.

Rosen, A., Hadzi-Pavlovic, D., Parker, G. \& Trauer, T. (2006). The Life Skills Profile: Background, Items and Scoring for the LSP-39, LSP-20 and the LSP-16. Available online at: http://blackdoginstitute.org.au/docs/LifeSkillsProfile.pdf. [Accessed 25 July 2013].

Rozenblatt, S. (2011). Behavioural Assessment of the Dysexecutive Syndrome. In: Kreuzer (ed.). Encyclopedia of Clinical Neuropsychology. New York: Springer Science \& Business Media.

Saklofske, D.H. \& Schoenberg, M.R. (2011). Wechsler Adult Intelligence Scale (All Versions). In: Kreuzer (ed.). Encyclopedia of Clinical Neuropsychology. New York: Springer Science \& Business Media. 
Schatz, P. (2011). Mini-Mental State Exam. In: Kreuzer (ed.). Encyclopedia of Clinical Neuropsychology. New York: Springer Science \& Business Media.

Schmidt, M. (1996). Rey auditory verbal learning test: A handbook. Los Angeles, CA: Western Psychological Services.

Schoenberg, M.R., Duff, K., Scott, J.G. \& Adams, R.L. (2003). An Evaluation of the Clinical Utility of the OPIE-3 as an Estimate of Premorbi WAIS-III FSIQ. The Clinical Neuropsychologist, 17, 308-321.

Scottish Government. (2007). Delivering for Mental Health and Substance Misuse: Consultation Draft. Edinburgh: Scottish Government.

Scottish Government. (2009). Changing Scotland's Relationship with Alcohol: A Framework for Action. Edinburgh: Scottish Government.

Scottish Intercollegiate Guidance Network. (2003). The management of harmful drinking and alcohol dependence in primary care. Edinburgh: Scottish Intercollegiate Guidance Network.

Shallice, T. \& Burgess, P.W. (1991). Deficits in strategy application following frontal lobe damage in man. Brain: A Journal of Neurology, 114, 2, 727-741.

Smith, I. \& Hillman, A. (1999). Management of Alcohol Korsakoff Syndrome. Advances in Psychiatric Treatment, 5, 271-278.

Taylor, R. \& O’Carroll. R. (1995). Cognitive estimation in neurological disorders, British Journal of Clinical Psychology, 34, 223-228.

Thomson, A.D., Guerrini, I. \& Marshall, E.J. (2012). The evolution and treatment of Korsakoff's syndrome: Out of sight, out of mind? Neuropsychology Review, 22, 81-92.

van den Berg, E., Nys, G.M.S., Brands, A.M.A, Ruis, C., van Zandvoort, M.J.E. \& Kessels, R.P.C. (2009). The Brixton Spatial Anticipation Test as a test for executive function: Validity in patient groups and norms for older adults. Journal of the International Neuropsychological Society, 15, 695-703.

Van Oort, R. \& Kessels, R.P.C (2009). Executive dysfunction in Korsakoff's syndrome: Time to revise the DSM criteria for alcohol-induced persisting amnestic disorder? International Journal of Psychiatry in Clinical Practice, 13, 78-81.

Venegas, J. \& Clark, E. (2011). National Adult Reading test. In: Kreuzer (ed.) Encyclopedia of Clinical Neuropsychology. New York: Springer Science \& Business Media.

Wager, T.D., Lindquist, M.A., Nichols, T.E., Kober, H. \& van Snellenberg, J.X. (2009). Evaluating the consistency and specificity of neuroimaging data using meta-analysis. NeuroImage, 45, s210-s221.

Wechsler, D. (1987). Wechsler Memory Scale-Revised. New York: The Psychological Corporation, 
Wechsler, D. (1998). The Wechsler Adult Intelligence Scale ( $3^{\text {rd }}$ ed.). New York: The Psychological Corporation.

Wechsler, D. (2001). Wechsler Test of Adult Reading San Antonio, TX: The Psychological Corporation.

Wester, A.J., van Herten, J.C., Egger, J.I.M. \& Kessels, R.P.C. (2013) Applicability of the Rivermead Behavioural Memory Test-Third Edition (RBMT-3) in Korsakoff's syndrome and chronic alcoholics. Neuropsychiatric Disease and Treatment, 9, 875-881.

Wetzel, C.D. \& Squire, L.R. (1982). Cued Recall in Anterograge Amnesia, Brain and Language, 15, 70-81.

Wilson, K. (2011). Alcohol-related brain damage: A $21^{\text {st }}$ Century management conundrum. The British Journal of Psychiatry, 199, 176-177.

Wilson, B.A., Greenfield, E., Clare, L et al. (2008). The Rivermead Behavioural Memory Test-Third Edition (RBMT-3), London, UK: Pearson Assessment.

Zahr, N.M., Kaufman, K.L. \& Harper, C.G. (2011) Clinical and pathological features of alcohol-related brain damage. Nature Reviews. Neurology, 7, 284-294. 
Table 1: Neurological methods of Assessments for ARBD

\begin{tabular}{|l|l|l|c|}
\hline Method of Assessment & Brief Description of instrument & $\begin{array}{l}\text { Number of } \\
\text { papers using } \\
\text { assessment }\end{array}$ & $\begin{array}{l}\text { Method of assessment } \\
\text { evaluated within } \\
\text { reviewed papers? }\end{array}$ \\
\hline Papers: Blansjaar et al, 1992 [1]; Caulo et al, 2005 [2]; Emsley et al, 1996 [3]; Fellgiebel et al, 2003 [4]; Paller et al, 1997 [5]; Reed et al, 2003 [6] & $3[1,3,6]$ & No \\
\hline $\begin{array}{l}\text { Magnetic Resonance } \\
\text { Imaging (MRI) }\end{array}$ & $\begin{array}{l}\text { Structural neuroimaging technique which } \\
\text { detects lesions in the brain by providing } \\
\text { cross-sectional images }\end{array}$ & \multicolumn{1}{|c|}{ No } \\
\hline $\begin{array}{l}\text { Functional Magnetic } \\
\text { Resonance Imaging (fMRI) }\end{array}$ & $\begin{array}{l}\text { Functional neuroimaging technique which } \\
\text { generates a spatial map of the brain to show } \\
\text { areas of neural activation }\end{array}$ & $3[3,4,5]$ & No \\
\hline $\begin{array}{l}\text { Positron Emission } \\
\text { Tomography (PET) }\end{array}$ & $\begin{array}{l}\text { Functional neuroimaging technique } \\
\text { involving the generation of a 2-dimensional } \\
\text { colour coded map depicting the } \\
\text { physiological processes within the brain }\end{array}$ & \\
\hline
\end{tabular}




\begin{tabular}{|c|c|c|c|}
\hline Method of Assessment & Brief Description of instrument & $\begin{array}{l}\text { Number of } \\
\text { papers using } \\
\text { assessment }\end{array}$ & $\begin{array}{l}\text { Method of assessment } \\
\text { evaluated within } \\
\text { reviewed papers? }\end{array}$ \\
\hline \multicolumn{4}{|c|}{$\begin{array}{l}\text { Papers: Beaunieux et al, } 1998 \text { [7]; Brand et al, } 2003 \text { [8]; Brand et al, } 2005 \text { [9]; Douglas and Wilkinson, } 1997 \text { [10]; Fujiwara et al, } 2008 \text { [11]; Joyce \& Robbins, } 1991 \text { [12]; Kessler et al, } \\
\text { 1986 [13]; Labudda et al, } 2010 \text { [14]; Maharasingam et al, 2013 [15]; Oscar-Berman et al, 2004 [16]; Pitel et al, } 2008 \text { [17]; Schoenberg et al, } 2010 \text { [18]; Taylor \& O'Carroll, } 1995 \text { [19]; Van } \\
\text { Den Berg et al, 2009 [20]; Van Oort and Kessels, 2009 [21]; Wester et al, } 2013 \text { [22]; Wetzel \& Squire, } 1982 \text { [23] }\end{array}$} \\
\hline \multicolumn{4}{|c|}{ Methods of assessing global cognitive and intellectual functioning } \\
\hline $\begin{array}{l}\text { Mini Mental State } \\
\text { Examination (MMSE) }\end{array}$ & $\begin{array}{l}\text { Brief } 11 \text {-item quantitative screening test to } \\
\text { assess the severity of cognitive impairment. } \\
\text { The MMSE takes } 5 \text { to } 10 \text { minutes to } \\
\text { complete }\end{array}$ & $6[5,8.9,11,14,17]$ & No \\
\hline $\begin{array}{l}\text { Wechsler Adult } \\
\text { Intelligence Scale (WAIS) }\end{array}$ & $\begin{array}{l}\text { Comprehensive intellectual functioning } \\
\text { assessment battery comprising } 6 \text { "verbal" } \\
\text { and } 5 \text { "performance" subtests }\end{array}$ & $\begin{array}{c}14 \\
{[1,3,5,6,7,8,9,10,11,13,1} \\
4,15,16,17]\end{array}$ & $\begin{array}{l}\text { Reliability coefficient > } \\
0.80\end{array}$ \\
\hline $\begin{array}{l}\text { National Adult Reading } \\
\text { Test (NART) }\end{array}$ & $\begin{array}{l}\text { 50-word untimed pronunciation test which } \\
\text { provides an estimate of premorbid } \\
\text { intellectual functioning }\end{array}$ & $6[5,6,9,11,12,15]$ & $\begin{array}{l}\text { Reliability coefficient > } \\
0.90\end{array}$ \\
\hline \multicolumn{4}{|c|}{$\begin{array}{l}\text { Miscellaneous assessments include: Achievement Measurement System; Clinical Dementia Rating Scale; Graded Naming } \\
\text { Test; Groningen Intelligence Test; Leistungsprufsystem; Mehrfach-Wahl-Wortschatztest; Oklahoma Premorbid Intelligence } \\
\text { Estimate-3 (OPIE-3); Raven's Standard Progressive Matrices }\end{array}$} \\
\hline \multicolumn{4}{|c|}{ Methods of assessing executive functioning } \\
\hline $\begin{array}{l}\text { Behavioural Assessment of } \\
\text { the Dysexecutive } \\
\text { Syndrome (BADS) }\end{array}$ & $\begin{array}{l}\text { 20-item test of executive functioning } \\
\text { comprising } 6 \text { subtests, designed to assess } \\
\text { everyday problems arising from executive } \\
\text { dysfunction }\end{array}$ & $2[15,21]$ & Inter-rater reliability 0.88 \\
\hline Trail Making Test (TMT) & $\begin{array}{l}\text { Test of attention, information processing } \\
\text { speed and cognitive flexibility. The test } \\
\text { comprises Trails and B and there is a time } \\
\text { limit of } 5 \text { mintues per trail }\end{array}$ & $6[3,10,11,14,15,16]$ & $\begin{array}{l}\text { Reliability coefficient } 0.79 \\
\text { Inter-rater reliability } 0.94\end{array}$ \\
\hline Word Naming (FAS) Test & $\begin{array}{l}\text { Phonemic verbal fluency test assessing the } \\
\text { generation of words beginning with } \mathrm{F}, \mathrm{A} \\
\text { and } \mathrm{S} \text {, with } 60 \text {-seconds allocated for each } \\
\text { word }\end{array}$ & $\begin{array}{c}10[3,5,6,8,9,11,12, \\
14,16,17]\end{array}$ & No \\
\hline $\begin{array}{l}\text { Wisconsin Card Sorting } \\
\text { Test (WCST) }\end{array}$ & $\begin{array}{l}\text { Non-verbal card sorting test assessing } \\
\text { abstract reasoning, mental flexibility and } \\
\text { problem solving. The WCST takes } \\
\text { approximately } 15 \text { minutes to administer and } \\
10 \text { minutes to score by hand }\end{array}$ & $6[5,8,9,12,14,16]$ & No \\
\hline Stroop Test & $\begin{array}{l}\text { Brief word-colour interference test } \\
\text { assessing the ability to inhibit a habitual } \\
\text { response to colour-word stimuli }\end{array}$ & $7[1,5,7,8,9,14,17]$ & No \\
\hline $\begin{array}{l}\text { Brixton Spatial } \\
\text { Anticipation Test (BSAT) }\end{array}$ & $\begin{array}{l}\text { Non-verbal test that assesses mental } \\
\text { flexibility and verbal memory. The test } \\
\text { takes around } 10 \text { minutes to administer }\end{array}$ & $1[14]$ & $\begin{array}{l}\text { Construct validity } \\
\text { coefficient }=0.74 ; \text { Test- } \\
\text { retest reliability }=0.61\end{array}$ \\
\hline \multicolumn{4}{|c|}{$\begin{array}{l}\text { Miscellaneous assessments include: Game of Dice Task; Porteus Mazes; Progressive Planning Test; Ruff Figural Fluency } \\
\text { Test; Test for Cognitive Estimation; Tower of Hanoi puzzle; Tower of London task }\end{array}$} \\
\hline \multicolumn{4}{|c|}{ Methods of assessing memory impairment } \\
\hline $\begin{array}{l}\text { Wechsler Memory Scale } \\
\text { (WMS) }\end{array}$ & $\begin{array}{l}\text { Comprehensive test comprising } 5 \text { indexes } \\
\text { (general memory, verbal memory, visual } \\
\text { memory, attention/concentration and } \\
\text { delayed recall) }\end{array}$ & $\begin{array}{c}9 \\
{[1,3,5,6,7,10,12,13,16]}\end{array}$ & No \\
\hline Memo Test & $\begin{array}{l}\text { Memory test assessing immediate and } \\
\text { delayed recall }\end{array}$ & $4[8,9,11,14]$ & No \\
\hline
\end{tabular}




\begin{tabular}{|c|c|c|c|}
\hline $\begin{array}{l}\text { Rey Osterreith Complex } \\
\text { Figure }\end{array}$ & $\begin{array}{l}\text { Non-verbal test of visual memory, } \\
\text { visuospatial construction ability and } \\
\text { executive functioning }\end{array}$ & $6[2,3,7,8,9,11]$ & No \\
\hline Fragmented Pictures Test & Test of implicit memory & $3[8,9,11]$ & No \\
\hline Doors and People & $\begin{array}{l}\text { Long-term memory test comprising } 4 \\
\text { categories (doors, people, shapes and } \\
\text { names), which assesses visual and verbal } \\
\text { recognition and recall. The test takes } \\
\text { approximately } 40 \text { minutes to administer }\end{array}$ & $1[15]$ & Inter-rater reliability 0.98 \\
\hline $\begin{array}{l}\text { Rivermead Behavioural } \\
\text { Memory Test }\end{array}$ & $\begin{array}{l}\text { Test of everyday memory deficits which } \\
\text { assesses verbal/nonverbal episodic } \\
\text { memory, spatial memory, prospective } \\
\text { memory and procedural memory }\end{array}$ & $2[21,22]$ & $\begin{array}{l}\text { Global Memory Index test } \\
\quad \text { sensitivity }(\geq 0.8) \\
\text { Global Memory Index test } \\
\quad \text { specificity }(\geq 0.6)\end{array}$ \\
\hline \multicolumn{4}{|c|}{$\begin{array}{l}\text { Miscellaneous assessments include: Auditory-Verbal Learning Test; Behavioural Face Recall and Recognition tests; Brown- } \\
\text { Peterson Paradigm; Cambridge Mental Disorders of the Elderly Examination; Corsi Block Tapping Task; Test; Ecological } \\
\text { Memory Test; Grober and Buschke Test; Memory Assessment Scales; Mirror Reading Test; N-2 paradigm; Public Events } \\
\text { Recognition List; Warrington Recognition Memory Test; Williams delayed Recall Test; Reading Speed Priming Test; } \\
\text { Release from Proactive Interference; Remember/Know/Guess Paradigm; Rey Auditory Verbal Learning Test; Signoret's } \\
\text { Memory Battery; Spondee Test; Verbal and Spatial Span tasks }\end{array}$} \\
\hline \multicolumn{4}{|c|}{$\begin{array}{l}\text { Other methods of assessment include: Affective Word Test; Cambridge Neuropsychological Test Automated Battery; } \\
\text { Concurrent Object Discrimination Task; Emotional Picture Task; Semantic Classification Test; Test Battery for Attentional } \\
\text { Performance; Visual Object Space Perceptual Battery (VOSP) }\end{array}$} \\
\hline
\end{tabular}


Table 3: Psychosocial Methods of Assessment

\begin{tabular}{|c|c|c|c|}
\hline Method of Assessment & Brief Description of instrument & $\begin{array}{l}\text { Number of } \\
\text { papers using } \\
\text { assessment }\end{array}$ & $\begin{array}{l}\text { Method of assessment } \\
\text { evaluated within } \\
\text { reviewed papers? }\end{array}$ \\
\hline \multicolumn{4}{|c|}{ Papers: Blansjaar et al, 1992 [1]; Douglas \& Wilkinson, 1997 [10]; Oscar-Berman et al, 2004 [16] Irvine and Wawhinney, 2008 [24]; Oudman and Zwart, 2012 [25] } \\
\hline Qualidem scale & $\begin{array}{l}\text { 37-item observational Quality of Life } \\
\text { (QoL) instrument with } 9 \text { subscales. The } \\
\text { Qualidem was specifically developed for } \\
\text { patients with mild-moderate dementia } \\
\text { living in residential care. }\end{array}$ & $1[24]$ & $\begin{array}{l}\text { Internal consistency of } \\
\text { individual subscales ranges } \\
\text { from } 0.59-0.89\end{array}$ \\
\hline Life Skills Profile (LSP) & $\begin{array}{l}\text { Standardised instrument for measuring } \\
\text { social and behavioural functioning, } \\
\text { comprising } 5 \text { subscales, including self-care } \\
\text { ability; social contact; communication; } \\
\text { responsibility and anti-social behaviour }\end{array}$ & $1[25]$ & No \\
\hline $\begin{array}{l}\text { Center for Epidemiologic } \\
\text { Studies Depression Scale } \\
\text { (CES-D) }\end{array}$ & $\begin{array}{l}\text { Standardised instrument for assessing } \\
\text { depression severity }\end{array}$ & $1[24]$ & No \\
\hline $\begin{array}{l}\text { Profile of Mood States } \\
\text { (POMS) }\end{array}$ & $\begin{array}{l}\text { Standardised measure of } 6 \text { affective mood } \\
\text { states over time, including Tension- } \\
\text { Anxiety; Vigour-Activity; Depression- } \\
\text { Dejection; Fatigue-Inertia; Anger-Hostility; } \\
\text { and Confusion-Bewilderment }\end{array}$ & $1[10]$ & No \\
\hline Geriatric Depression Scale & $\begin{array}{l}\text { Measure of depression designed for use } \\
\text { with elderly long-term care patients }\end{array}$ & $1[10]$ & No \\
\hline Hamilton Depression Scale & $\begin{array}{l}\text { Standardised instrument for assessing } \\
\text { depression severity }\end{array}$ & $1[16]$ & No \\
\hline $\begin{array}{l}\text { Brief Psychiatric Rating } \\
\text { Scale }\end{array}$ & $\begin{array}{l}\text { Rating scale which screens for } \\
\text { psychopathology such as depression, } \\
\text { anxiety and psychosis }\end{array}$ & $1[1]$ & No \\
\hline
\end{tabular}


Figure 1: Flow of information through systematic review

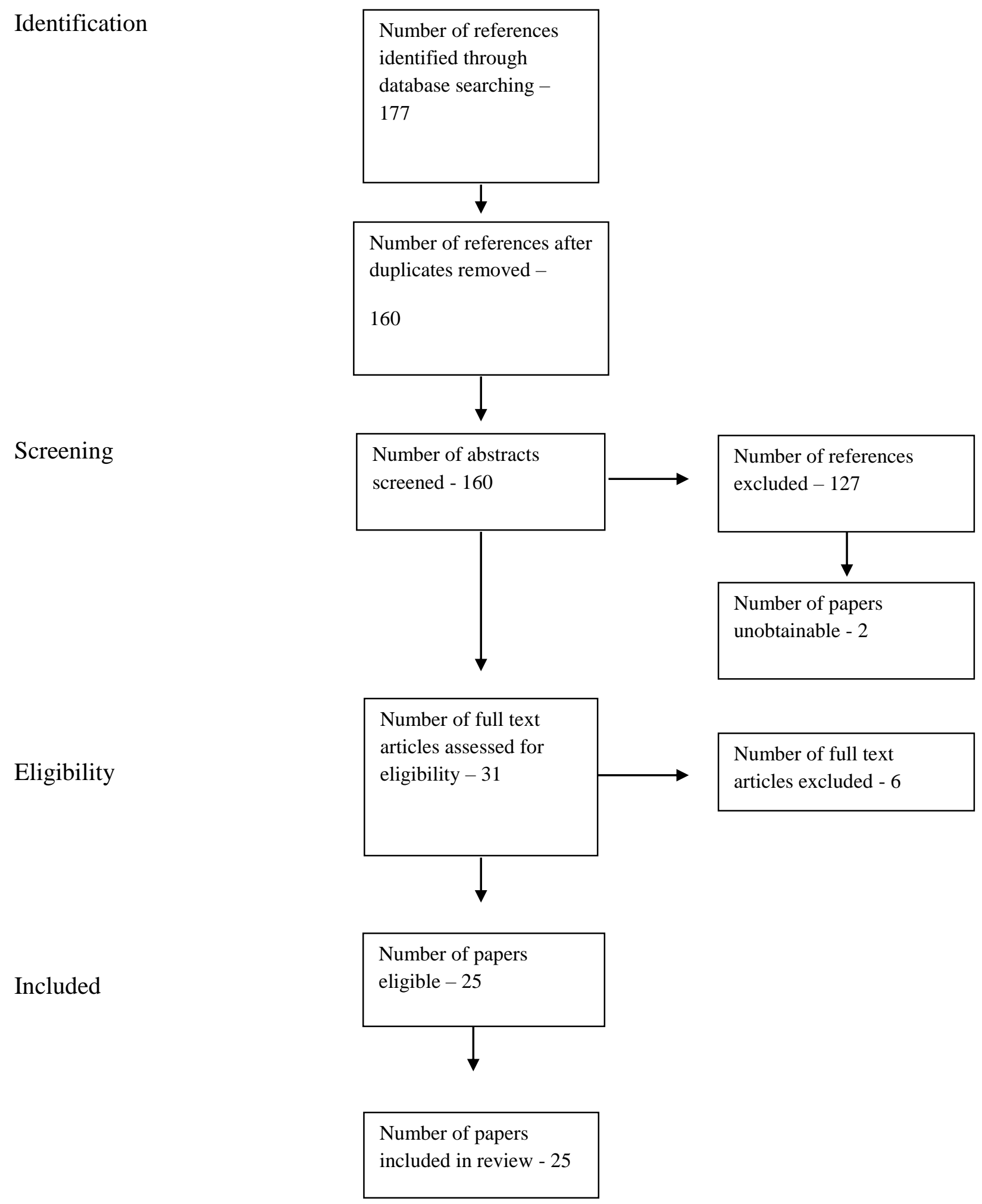

